\title{
At Right Angles
}

At Right Angles (AtRiA for short) is a new magazine in mathematics, written for teachers and high school students. It is published jointly by Azim Premji University and Community Math Centre, Rishi Valley School (KFI). It is freely available in e-form as a PDF file.

The objectives of the publication are: To publish a mathematics magazine for mathematics teachers, students and teacher education students, which will: act as a source of inspiration and intellectual enjoyment for teachers and students alike; offer a vision of Mathematics as a subject to be explored and enjoyed; create in its readers a love of problem solving, and an appreciation of good writing; offer teachers a platform for networking; and cumulatively provide a resource base of materials to math teachers.

There is a serious need today to create viable platforms where teachers and children across the country can read about mathematical matters, possibly not in the regular curriculum, where they can solve non-routine problems, where they can contribute, where beautiful results in school level mathematics can be written about and discussed. The publishers of At Right Angles believe this purpose is best served by a magazine available simultaneously in print and online form.

(It may be noted that the acronym 'AtRiA' has a secondary meaning which has significance: it refers to an open, light-filled space. The editors hope that the magazine will provide such a space for a discourse on mathematics and mathematics education!)

The articles will be addressed to math teachers and students (classes 8-12), and members of the public who have an interest in mathematics and mathematics education. In addition to 'Feature' articles in pure and applied mathematics the magazine will have a 'Classroom' section; a 'Technology' section, with articles on computer algebra, geometry software, and so on; a 'Pull-out' for primary school math teachers (dealing with teaching strategies and activities for teaching difficult concepts); a 'Problem Corner' (though the focus will not be on the math Olympiads); a 'Reviews' section; and so on. The following online documents give details about the magazine and invite contributions from interested persons:

- https://docs.google.com/document/d/1saPWR8tWCUqQBOTB64Ju6mHg6iqGeTEj1458O LdgZzA/edit

- https://docs.google.com/document/d/1ChmmGY6BUTWHqe5-h32bEeGwCRAqzjPWaMGiWVwvIsU/edit

Issues may be freely downloaded at the following link (only registration is required):

http://azimpremjiuniversity.edu.in/content/publications.

Shailesh A Shirali

Chief Editor, At Right Angles 